ORIGINAL RESEARCH PAPER

\title{
IN VITRO ANTIOXIDANT POTENTIAL AND ANTIMICROBIAL ACTIVITY OF SOME CAMEROONIAN PLANT EXTRACTS
}

\author{
JAMES RONALD BAYOÏ ${ }^{1}$, GABRIELA RAPEANU ${ }^{* 2}$, NICOLETA STANCIUC ${ }^{2}$, MIHAELA \\ COTARLET $^{2}$, OANA EMILIA CONSTANTIN ${ }^{2}$, FRANCOIS-XAVIER ETOA ${ }^{3}$ \\ ${ }^{* 1}$ Department of Biological Sciences, Faculty of Sciences, University of Maroua, 814 Maroua, \\ Cameroon \\ ${ }^{2}$ Department of Food Science, Engineering and Applied Biotechnology, Faculty of Food Science and \\ Engineering, Dunarea de Jos University of Galati, 111 Domneasca Street, 800201 Galati, Romania \\ ${ }^{3}$ Department of Microbiology, Faculty of Sciences, University of Yaoundé I, 812 Yaoundé, Cameroon \\ * Corresponding author: Gabriela.Rapeanu@ugal.ro
}

Received on 26 April 2021

Revised on 22 November 2021

\begin{abstract}
A study on Cameroonian edible and medicinal plants was undertaken to assess their potential as food preservatives and natural food colorants. The ultrasound-assisted technique was used for the extraction of bioactive compounds. A total of 16 extracts prepared from 7 plants (Aframomum melegueta S., Ageratum conyzoides L., Cympobogon citratus Stapf, Garcinia kola Heckel, Lantana camara L., Nauclea diderrichii, Vernonia amygdalina) were assayed to detect phytochemicals and assess antioxidant potential using the scavenging DPPH radical method and antimicrobial activity $(10 \mathrm{mg} / \mathrm{mL})$ against ten microorganisms by the agar well diffusion method. The ethanolic extract from $L$. camara leaves revealed the highest polyphenols and flavonoids contents. In contrast, the hexane/acetone extract from A. conyzoides and L. camara leaves had the highest chlorophyll a (Chl a) and chlorophyll b (Chl b) contents, whereas the highest carotenoid content was found in L. camara leaves. The ethanol extracts exhibited more significant antioxidant activity than hexane/acetone extracts. All seven plants $(100 \%)$ inhibited the growth of at least one tested foodborne and spoilage bacteria and fungi. The germination of both Bacillus spp. spores were also affected. The hexane/acetone extracts were by far the best antimicrobial agent, and extract from $L$. camara leaves was one of the most effective, with a large antimicrobial spectrum. The antimicrobial activity of extracts was correlated to the amount of carotenoids and chlorophylls. HPLC-DAD revealed bioactive compounds as chlorogenic and caffeic acids found as major phenols in ethanolic extract of $L$. camara leaves, whereas lutein, carotene, and zeaxanthin were the specific carotenoids present in hexane/acetone extract of the same plant.
\end{abstract}

Keywords: Cameroonian plants extracts, phytochemicals, antioxidants, antimicrobial activity

https://doi.org/10.35219/foodtechnology.2021.2.07 


\section{Introduction}

Food poisoning and food safety resulting from microbial deterioration remain a concern for consumers and the food industry. According to the World Health Organization, foodborne hazards are annually responsible for 137,000 deaths and 91 million acute illnesses in Africa, more than 5000 deaths and 76 million foodborne illnesses in the USA, and 100,000 cases of food poisoning in England and Wales (Cock and van Vuuren, 2015). To counteract the perishable nature of food products due to bacterial and fungal growth and to improve food color and effectively prevent food poisoning, many banned synthetic chemicals are still used as food preservatives and food colorants in some countries (Amchova et al., 2015). In recent years, foods preserved with natural additives have become very popular because of the excellent consumer awareness and concern regarding synthetic chemical additives (Lucera et al., 2012). Consumers perceive natural colorants as safer than synthetic ones, which are harmful because of their possible links to hyperactivity in children and allergenicity in sensitive populations (Amchova et al., 2015). Apart from their potent ability to color foods, natural colorants provide health benefits, organoleptic features and also act as antioxidants and even preservatives as food ingredients (Rodriguez-Amaya, 2016). Indeed, natural crude extracts from plant species used in traditional medicine may represent valuable sources for such new natural preservatives and colorants considered as safe, effective, and acceptable (Meot-Duros et al., 2008). It is estimated that there are 250,000 plant species on the earth, and only one-tenth of these have been explored until date (Negi, 2012). There are approximately 60,000 plant species in Africa, and up to $90 \%$ of the population of many African countries still rely on plants as a source of medicines. However, Africa has only contributed to 83 of the world's 1100 leading commercial medicinal plants. Plant oils and extracts have been used for thousands of years; they serve many purposes, such as food preservatives and therapeutic agents (Hintz et al., 2015). Given that the use of plant extracts with known biological properties can be of great significance in food preservation and dyeing, the search for natural substances from plants with antimicrobial activities, antioxidant potentials, and dyeing property constitutes a great interest of research and in industrial innovations. In this context, extracts from seven indigenous Cameroonian plants used as vegetables, spices, and medicines were investigated.

Aframomum melegueta K. Schum. is also known as African jujube or guinea pepper (Onoja et al., 2014). In Cameroon, where its indigenous names include "ndôn" in the Bassa dialect, this plant is consumed as an edible spice and used in the folk headache treatment. Previous studies showed that different plant parts act as immune enhancers and have healing potential (Olajuyigbe et al., 2020). Ageratum conyzoides L. is an annual herb with a long history of traditional medicinal uses in many tropical countries worldwide. The concentrate or infusion of the plant is used in folk medicine to treat various ailments such as malaria, dysentery, diarrhea (Ladoh-Yemeda et al., 2016). Cymbopogon citratus Stapf, commonly known as lemongrass, is an aromatic plant used in herbal medicine for a wide range of applications (Prakash et al., 2016). In folk medicine, this plant treats 
cough, gastrointestinal disorders, malaria (Ladoh-Yemeda et al., 2016). The decoction of $C$. citratus leaves is widely consumed alone as a relaxing herbal tea and flavoring agent. Studies on its phytochemical content revealed the presence of various essential oils in the plant (Ascension et al., 2017). Garcinia kola Heckel also called bitter kola, is mainly found in the rainforest region of Central and West Africa (Esiegwu et al., 2014). This plant is a medium-sized tree, which produces large fruits, containing 3-4 seeds coated brown. G. kola is used both as food and medicine (Ladoh-Yemeda et al., 2016). Ethnobotanical studies showed that this plant is used to fight against gastroenteritis and some infectious diseases (LadohYemeda et al., 2016). Lantana camara L. is a flowering ornamental plant, mainly found in the American and African continents (Ladoh-Yemeda et al., 2016). The leaf extracts are widely used in folk medicine to treat malaria, stomach ache, fever, and cancers (Ladoh-Yemeda et al., 2016). Nauclea diderrichii (De Wild.) Merr is an evergreen savannah tree widely used in traditional folklore medicine to treat indigestion, diabetes, and stomachache (Agnaniet et al., 2016). Vernonia amygdalina known as the bitter leaf is one of the most studied plants in Africa. This plant is consumed as a vegetable and used in folk medicine in many African countries. Researchers have recorded that this plant is used to control gastrointestinal parasites, treat malaria, boast immunity of HIV patients and stomach pains (Ladoh-Yemeda et al., 2016).

In Cameroon, many studies on the biological properties of indigenous plants deal essentially with the plant oils (Ascension et al., 2017; Voundi et al., 2015), but enough has to be done to explore the urge potential of the plant extracts. Furthermore, no information has been reported on crude extracts as a source of natural food additives. In this study, we have highlighted for the first time a collaborative study on the phytochemical, antioxidant, and antimicrobial properties of the extracts of seven plants to assess their biological activities and to confirm their potential use as food preservatives and natural colorants. Therefore, the purpose of this study was (i) to investigate the phytochemical profile and antioxidant activity of the plant extracts obtained from two solvent systems, (2i) to evaluate their antimicrobial property (3i) to characterize the phytochemical content of the most active extract.

\section{Materials and methods}

\section{Collection of plant material and extraction}

Native Cameroonian plants used in this work were either used as food or identified as plants with ethnobotanical interest to treat food poisoning associated with diarrhea and dysentery. The plants chosen were harvested or purchased in April 2018 in Maroua (Far North, Cameroon), Yaoundé (Centre, Cameroon), and Douala (Littoral, Cameroon). The plants' identity was authenticated by the botanical experts of the national herbarium, Cameroon (Table 1). Plants collected were washed and dried shade in an oven at $45^{\circ} \mathrm{C}$ for a day. The dried material was milled into powder using an electrical blender (MLynek Laboratory JNY Tip WZ/2, Poland) and kept in sealed containers for further use. The extracts were 
prepared using ultrasound-assisted extraction protocol as described by Dadi et al. (2019). One gram of each plant powder was weighed in four Eppendorf tubes. Ten milliliters of ethanol $70 \%$ or hexane/acetone $(3: 1, \mathrm{v} / \mathrm{v})$ were added. The samples were left at $35^{\circ} \mathrm{C}$ for $30 \mathrm{~min}$ in an ultrasonic bath (MRC AC-150H series, UK) designed with a fixed frequency of $35 \mathrm{kHz}$ and power intensity of $150 \mathrm{~W}$. The samples were centrifuged three times at $5000 \mathrm{rpm}$ at $4^{\circ} \mathrm{C}$ for 30 minutes. The resulting supernatants were collected, centrifuged once at $9000 \mathrm{rpm}$ for $10 \mathrm{~min}$ at $4^{\circ} \mathrm{C}$, and concentrated in an air-dried vacuum (Rotavapor R-124, Buchi, Switzerland). Ethanolic and hexane/acetone dried extracts of each plant were stored at $4^{\circ} \mathrm{C}$ for further analysis.

Table 1. Common names and local usage of the plants used.

\begin{tabular}{llll}
\hline Plant names & $\begin{array}{l}\text { Common/local } \\
\text { names }\end{array}$ & Family & Part used \\
\hline Aframomum melegueta S. & -/ndon & Zingiberaceae & Seeds \\
Ageratum conyzoides L. & -/ Kaïtoro & Asteraceae & Entire plant \\
Cympobogon citratus Stapf & Citronella & Poaceae & Leaves \\
Garcinia kola Heckel & Bitter kola & Clusiaceae & fruits \\
Lantana camara L. & Lantana & Verbenaceae & Leaves, rods \\
Nauclea diderrichii & Bilinga & Rubiaceae & Stem bark \\
Vernonia amygdalina & Bitter & Asteraceae & Leaves \\
\hline
\end{tabular}

\section{Chemicals}

Folin-Ciocalteu reagent, 2,2- diphenyl- 1- picrylhydrazyl, 6-hydroxy-2,5,7,8tetramethylchromane-2-carboxylic acid, gallic, caffeic, chlorogenic and hydrochloric acids, catechin, lutein, zeaxanthin, ß-carotene, sodium carbonate, sodium hydroxide, sodium acetate, sodium nitrite, potassium chloride, aluminum chloride, ethanol, methanol, acetone, n-hexane, Tryptic Soy Broth, Nutrient Agar, Muller Hinton Agar, Sabouraud Agar were obtained from Sigma (Steinheim, Germany) and Merck (Darmstadt, Germany).

Determination of pigment content: chlorophyll a (Chl a), chlorophyll b (Chl b), and carotenoids

The pigment content of hexane/acetone plant extracts was determined spectrophotometrically according to the modified protocol used by Elbatanony et al. (2019). Three milliliters of each plant extracts prepared at $1 \mathrm{mg} / \mathrm{mL}$ were put into a reading tube, and the absorbance values were recorded at $\lambda=450 \mathrm{~nm}, 645$ $\mathrm{nm}$, and $663 \mathrm{~nm}$. The content of $\mathrm{Chl} \mathrm{a,} \mathrm{Chl} \mathrm{b}$, and carotenoids were calculated using the formula (1), (2), and (3), respectively:

Chlorophyll a $(\mathrm{mg} / \mathrm{g})=\left(11.75 \times \mathrm{Abs}_{663}\right)-\left(2.35 \times \mathrm{Abs}_{645}\right)$

Chlorophyll b $(\mathrm{mg} / \mathrm{g})=\left(18.61 \times \mathrm{Abs}_{645}\right)-\left(3.96 \times \mathrm{Abs}_{663}\right)$ 
Carotenoids $(\mathrm{mg} / \mathrm{g})=\left(\mathrm{Abs}_{450} \times \mathrm{Vs} \times \mathrm{D}_{\mathrm{f}}\right) /(\mathrm{m} \times 1 \times \xi)$

where $\mathrm{Abs}_{450}, \mathrm{Abs}_{645}, \mathrm{Abs}_{663}$ are O.D. values at $450 \mathrm{~nm}, 645 \mathrm{~nm}, 663 \mathrm{~nm}$, Vs is volume of solution; $\mathrm{D}_{\mathrm{f}}$ is dilution factor; $\mathrm{l}=1 ; \mathrm{m}=9.35 ; \xi=2590$

\section{Determination of total phenolic content}

Total phenolic contents were analyzed using the Folin-Ciocâlteu method as described by Bolea and Vizireanu (2017). Briefly, $100 \mu \mathrm{L}$ of extract $(1 \mathrm{mg} / \mathrm{mL})$ was mixed with $7.9 \mathrm{~mL}$ of deionized water and $0.5 \mathrm{~mL}$ of Folin-Ciocalteu reagent $(0.25$ $\mathrm{mol} / \mathrm{L}$ ). After 10 minutes, $1.5 \mathrm{~mL}$ of $20 \% \mathrm{Na}_{2} \mathrm{CO}_{3}$ solution was added, and the mixture was kept in the dark for one h. Finally, the absorbance was measured against a blank at $\lambda=765 \mathrm{~nm}$. Gallic acid was used as a standard $(50-250 \mathrm{mg} / \mathrm{L})$, and the total phenolic content was expressed as gallic acid equivalent per gram of dry weight (mg GAE/g DW).

\section{Determination of flavonoids content}

Flavonoids contents were assessed using a modified aluminum chloride colorimetric method as described by Pękal and Pyrzynska (2014). $250 \mu 1$ of the plant extracts $(1 \mathrm{mg} / \mathrm{mL})$ were diluted with $1.25 \mathrm{~mL}$ of deionized water, and 0.075 $\mathrm{mL}$ of $5 \% \mathrm{NaNO}_{2}$ solution was added. After 5 minutes in the dark, $0.15 \mathrm{~mL}$ of $10 \% \mathrm{AlCl}_{3}$ solution was introduced. After 6 minutes, $0.5 \mathrm{~mL}$ of $1 \mathrm{M} \mathrm{NaOH}$ and $0.775 \mathrm{~mL}$ of deionized water were added into the reaction mixture, and absorbance was read at $\lambda=410 \mathrm{~nm}$ using a UV-Vis spectrophotometer (Libra S22, Biochrom, UK). Catechin was used as standard (20-100 $\mathrm{mg} / \mathrm{L})$, and the flavonoids content was expressed as catechin equivalent per gram of dry weight (mg CE/g DW).

\section{Determination of the antioxidant activity of the plant extracts}

The DPPH assay was determined following the colorimetric method described by Shahinuzzaman et al. (2020) with slight modifications. A volume of $0.1 \mathrm{~mL}$ of extracts $(1 \mathrm{mg} / \mathrm{mL})$ was mixed with $3.9 \mathrm{~mL}$ of diluted $(1: 10) \mathrm{DPPH} / \mathrm{methanol}$ solution. Then, the preparation was kept for $90 \mathrm{~min}$ at room temperature in the dark. The decrease in the absorbance of the mixture was spectrophotometrically read at $\lambda=517 \mathrm{~nm}$. Trolox was used as standard $(0.125 \mathrm{mg} / \mathrm{mL})$, and the radical scavenging activity was expressed as the percentage of inhibition based on equation (4):

$\mathrm{DPPH}_{\text {scavenging activity }}(\%)=[(\mathrm{Abs}$ Control $-\mathrm{Abs}$ Sample or Trolox $) / \mathrm{Abs}$ Control $]$ x 100

where $\mathrm{Abs}_{\text {Control }}$ is the OD value of the DPPH solution only, $\mathrm{Abs}_{\text {Sample or Trolox }}$ is the OD value of the DPPH solution mixed either with extracts or Trolox solution.

\section{Antimicrobial activity of the plant extracts}

\section{Test microorganisms}

The following strains were used as test organisms: Bacillus subtilis MIUG B1; Bacillus cereus MIUG B2; Lactobacillus plantarum MIUG BL3; Listeria monocytogenes EGD-e and Staphylococcus aureus ATCC 25923; Salmonella agona MIUG BP1; Saccharomyces spp. MIUG D8; Penicillium expansum MIUG M11; Aspergillus niger MIUG M64; Kluyveromyces spp. MIUG M26. The strains 
were obtained from the collection of Integrated Center for Research, Expertise and Technological Transfer in Food Industry BioalimentTehnIA, "Dunarea de Jos" University of Galati, Romania.

\section{Antimicrobial screening}

Screening of extracts was determined using a modified agar well-diffusion technique as described by Zhang et al. (2020). Before use, bacteria were cultivated on Muller Hinton Broth at $35^{\circ} \mathrm{C}$ until was reached $0.5 \mathrm{McFarland}\left(\sim 10^{8} \mathrm{CFU} / \mathrm{mL}\right)$ (Kirby-Lee, 2019). The spores of Bacillus strains were produced on sporulation agar as described by Bayoï et al. (2014) and heat-activated $\left(80^{\circ} \mathrm{C}\right.$ for $\left.10 \mathrm{~min}\right)$, the final spore concentration was adjusted at $10^{8}$ spores/ mL. The molds spores were collected from 7 days-old cultures in $10 \mathrm{~mL}$ of sterile distilled water, and the final concentration was adjusted to $10^{7}$ spores/ $\mathrm{mL}$. The yeasts were subculture onto Sabouraud dextrose agar at $35^{\circ} \mathrm{C}\left( \pm 2^{\circ} \mathrm{C}\right)$ for $24 \mathrm{~h}$ and the yeast inoculum was prepared by picking five distinct colonies and suspended in $5 \mathrm{~mL}$ of sterile saline water. The resulting suspension is vortexed for 15 seconds, and it is adjusted to obtain a yeast stock suspension of $10^{7}$ cells per $\mathrm{mL}$ (Espinel-Ingroff, 2007). For the agar well-diffusion technique, one hundred microliters of each microbial suspension were spread on nutrient plates with formed wells of $9 \mathrm{~mm}$ diameter, and after that, each well was filled with $100 \mu \mathrm{L}$ of the different extracts prepared at 10 $\mathrm{mg} / \mathrm{L}$ concentration. Tween $80(0.2 \%)$ and sterile water were used as negative controls and to dissolve hexane/acetone and ethanolic extracts. Gentamycin and Nystatin $(1 \mathrm{mg} / \mathrm{mL})$ were used as a positive control for bacteria and fungi species, respectively. After a pre-diffusion of 20 minutes at room temperature, the plates were incubated at $37^{\circ} \mathrm{C}$ for $24 \mathrm{~h}$ for bacteria and $25^{\circ} \mathrm{C}$ for 72 hours for fungi. The antimicrobial activity was assessed by measuring the inhibition zone (IZ) diameter $(\mathrm{mm})$ around the well using a caliper. This screening test was carried out to select the most active extracts against the test microorganisms.

\section{Microbial susceptibility test}

This test was used to determine the minimum inhibitory concentration (MIC), minimum fungicidal concentration (MFC), and the minimum bactericidal concentration (MBC) of extracts using the protocol of Andrews (2001) with minor modifications. Firstly, each extract was serially diluted to obtain concentrations ranging from $10 \mathrm{mg} / \mathrm{L}$ to $0.156 \mathrm{mg} / \mathrm{L}$. Secondly, $1 \mathrm{~mL}$ of extract and dilutions was mixed with $1 \mathrm{~mL}$ of the overnight culture of Muller Hinton Broth, corresponding to $0.5 \mathrm{McFarland}$ standard. After incubation at $35 \pm 2^{\circ} \mathrm{C}$ for $18-20 \mathrm{~h}$, the tubes were observed for growth, and MIC value was recorded as the lowest concentration where visible growth was not observed. The minimum concentration for the inhibition of spore germination ( $\mathrm{MICg}$ ) was determined as described by Voundi et al. (2015). Briefly, the spore suspensions $\left(10^{6}\right.$ spores $\left./ \mathrm{mL}\right)$ were inoculated in $2 \mathrm{~mL}$ of nutrient broth at a low concentration of extracts to avoid its effect on vegetative growth. Tubes were incubated for $24 \mathrm{~h}$ at the optimal growth temperature. The MBCs were determined by inoculation of $2-3 \mu \mathrm{L}$ of the culture corresponding to the minimum inhibitory concentration and spread on a nutrient plate and incubated at the optimal growth temperature for 24 hours. The minimum fungicidal 
concentration (MFC) was obtained by spreading $10 \mathrm{ml}$ of each serial dilution on Sabouraud dextrose agar. Plates were incubated at $28^{\circ} \mathrm{C}$ for $72 \mathrm{~h}$. The MFC was defined as the lowest extract concentration that yielded three or fewer colonies (Silveira et al., 2009). The extract was microbiocidal when MB(F)C:MIC ratio was between 1 and 2, and microbiostatic when the ratio was superior to 2 (Breda et al., 2016).

\section{HPLC analysis of individual phenolic and pigments}

The analyses of phenolic compounds of ethanolic extract and pigments of hexane/acetone extracts were performed using HPLC-DAD (Shimadzu Co, Japan), equipped with an autosampler model SIL-20A, a Shimadzu pump (LC-20AT), diode array detector model SPD-M20A. The separation was carried out in the C18 column $(150 \mathrm{~mm} \times 4 \mathrm{~mm}, 5 \mu \mathrm{m})$. The elution solvents were $6: 3$ methanol/sodium acetate (A) and 2.3\% methanol (B). Total run time was 30 min for pigments analysis with the gradient of $15 \%$ (B) for 3 min changing to $50 \%$ (B) in $7 \mathrm{~min}$, and reaching at $100 \%$ (B) in $20 \mathrm{~min}$. Concerning the analysis of the phenolic compounds, the entire run was $60 \mathrm{~min}$ with the elution programmed as follow: $10 \%$ (B) for $2 \mathrm{~min}$; 30\% (B) until $10 \mathrm{~min}$; regulated rise to $80 \%$ (B) at a rate of 10\%/8 min for $40 \mathrm{~min}$ and finally $100 \%$ (B) at a rate of $10 \% / 5 \mathrm{~min}$ for $10 \mathrm{~min}$. The flow rate was $1 \mathrm{~mL} / \mathrm{min}$, and the volume injected was $20 \mu \mathrm{L}$. Identification of compounds was performed based on their retention time with those of referenced standards. When standards were not available, identification was based on DAD spectra and data reported in the literature.

\section{Data analysis}

The data were mean of triplicate analysis \pm standard deviation. The parameters evaluated were subjected to one-way ANOVA to determine the mean differences among the extracts. When significant differences in ANOVA $(p<0.05)$ were detected, the HSD Tukey's multiple range test was applied at $p<0.05$. Principal Component Analysis (PCA) and Hierarchical Cluster Analysis (HCA) were performed to analyze the correlation between the quantitative variables evaluated from extracts, and the relationship between the plant extracts, using SPSS Statistical program (SPSS version 20, IBM Inc., Armonk, New York, USA).

\section{Results and discussion}

\section{Phytochemical characterization of the extracts}

Table 2 presents $\mathrm{Chl}$ a, Chl b, carotenoids, phenols, and flavonoid contents of ethanolic and hexane/acetone extracts. Phenols and flavonoids contents in ethanolic extracts were higher than those in hexane/acetone extracts. The extraction of phenols and flavonoids was significantly $(p<0.05)$ higher in ethanolic extracts for the $L$. camara leaves $(110 \pm 0.5 \mathrm{mg} \mathrm{GAE} / \mathrm{g}$ and $158 \pm 1.6 \mathrm{mg} \mathrm{CE} / \mathrm{g}$, respectively). The hexane/acetone extraction revealed a higher content of phenols in the $A$. melegueta seeds and for the flavonoids in the $L$. camara leaves $(50 \pm 0.1 \mathrm{mg} \mathrm{CE} / \mathrm{g})$. 


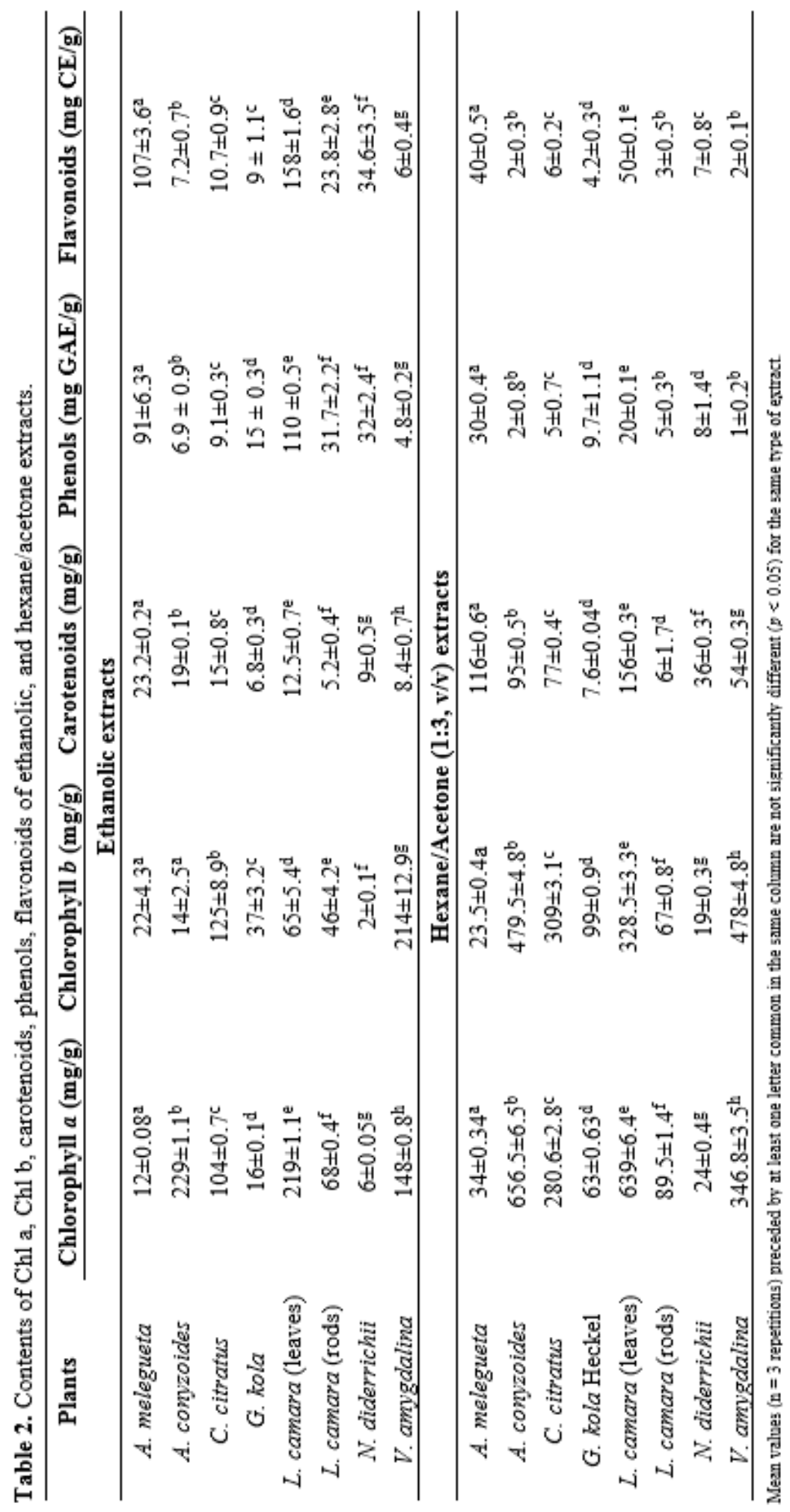




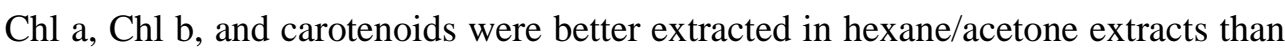
in ethanolic extracts. The $\mathrm{Chl}$ a contents were significantly important in hexane/acetone extracts of $A$. conyzoides $(656.5 \pm 6.5 \mathrm{mg} / \mathrm{g})$ and $L$. camara leaves $(639 \pm 6.4 \mathrm{mg} / \mathrm{g})$. The highest contents of $\mathrm{Chl} \mathrm{b}$ were found in hexane/acetone extracts of A. conyzoides $(479.5 \pm 4.8 \mathrm{mg} / \mathrm{g})$ and $V$. amygdalina leaves $(478 \pm 4.8)$.

The differences between the major chlorophyll types ( $\mathrm{Chl} \mathrm{b}$ becoming higher than Chl a) can be explained by several stressed conditions induced to plants (Idhan et al., 2018). Moreover, a Chl a and $\mathrm{Chl} b$ decreased ratio indicates that photosystem II (PSII) reaction centers can be more influenced than light-harvesting complexes (LHC), Chl b being only in LHC, whereas Ca are part of PSII (Contreras et al., 2013). The highest contents of carotenoids were found in hexane/acetone extracts of $L$. camara leaves $(156 \pm 0.3 \mathrm{mg} / \mathrm{g})$, almost ten times higher than in the ethanolic extracts.

The antioxidant potential of extracts is shown in Figure 1. The results reveal that all the extracts tested exhibited an antioxidant activity with significant differences $(p<0.05)$ between ethanolic and hexane/acetone extracts. The scavenging activity of ethanolic extracts was significantly higher $(\mathrm{p}<0.05)$ than hexane/acetone extracts. The ethanolic extracts from A. melegueta seeds $(83.81 \%)$, L. camara leaves (84.4\%), and G. kola fruits $(63.6 \%)$ had the highest scavenging activity values. Furthermore, the scavenging activities of the same extracts were significantly higher $(\mathrm{p}<0.05)$ than the activity of Trolox $(53.75 \%)$ used as standard. Among hexane/acetone extracts, the fruit of $G$. kola recorded the best scavenging activity $(47.6 \%)$.

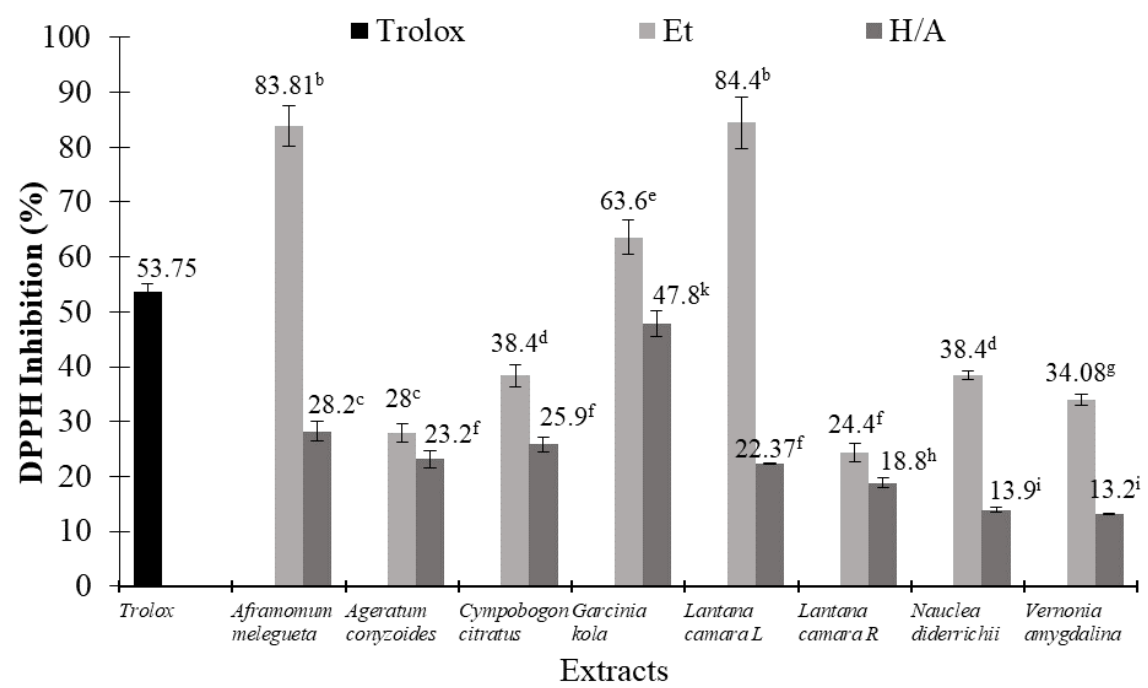

Figure 1. DPPH scavenging inhibition of the plant extracts. Trolox has been used at the concentration of $0.125 \mathrm{mg} / \mathrm{mL}$. Mean values that do not share the same superscript letters are significantly different at $p<0.05$. Et - Ethanolic extracts; HA - Hexane/Acetone 
Ethanolic extracts displayed higher phenolic contents than hexane/acetone (1:3, $\mathrm{v} / \mathrm{v}$ ) extracts. This might be linked to the polarity of the solvent. It has been reported that solvent polarity increases phenolic compounds' solubility (Złotek et al., 2016). Therefore, adding a small quantity of water in an organic solvent increases the relative polarity of the solvent leading to the mass transfer process and enhancing solubility of the phenolic compounds from the plant matrix (Dahmoune et al., 2014). The high contents in natural pigments associated with hexane/acetone extracts were also due to the polarity of solvent used. Hexane and acetone are both non-polar solvents that can easily solubilize lipid-soluble pigments such as chlorophylls and carotenoids. At the same time, water-soluble molecules such as phenolic compounds were hardly solubilized by the same nonpolar solvent, justifying the lowest contents of phenolics in hexane/acetone extracts.

Similarly, previous studies revealed that the phenolic content of plant extract is highly correlated to antioxidant activity (Prakash et al., 2016). Meanwhile, according to the scavenging test, three ethanolic extracts were more antioxidants than Trolox. Among these extracts, L. camara leaves have been identified as one of the most antioxidant extracts. The phytochemical composition of this plant might explain this result.

\section{Phenolic and pigments composition of L. camara}

Based on the high phytochemical content coupled to the best antioxidant and antimicrobial activities, HPLC-DAD of ethanolic extract of $L$. camara leaves was carried out and led to the identification of seven known phenolic compounds, mainly phenolic acids (Figure 2).

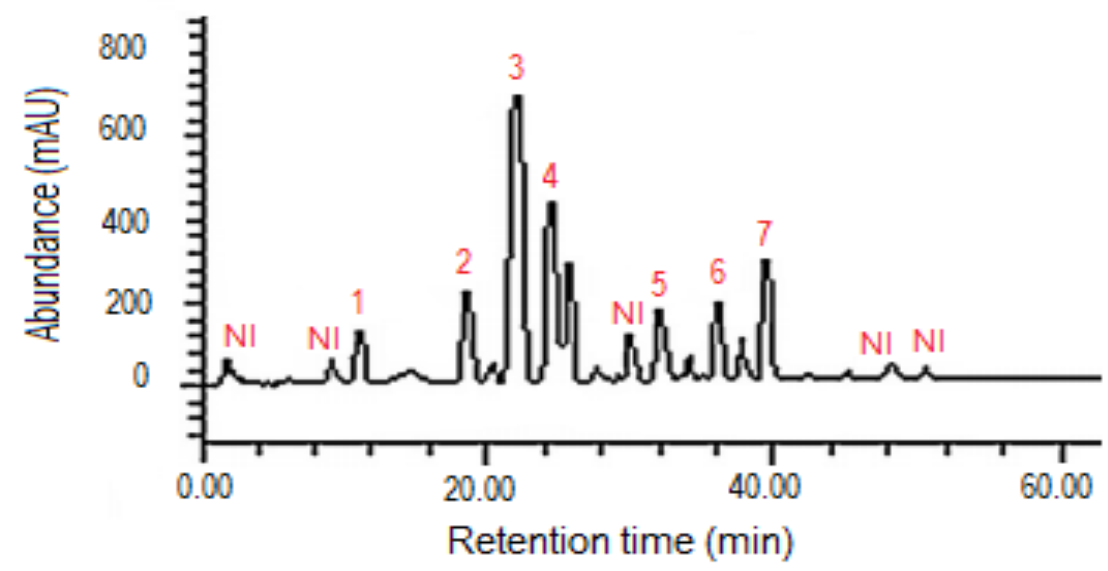

Figure 2. HPLC chromatogram of phenols and flavonoids of ethanolic extract from Lantana camara. NI.: No Identified.

The identified compounds in the ethanolic extract of $L$. camara were gallic acid (peak 1, RT: $14.92 \mathrm{~min}$ ), catechin (peak 2, RT: $19.39 \mathrm{~min}$ ), ellagic acid (peak 5, 
RT: $32.05 \mathrm{~min}$ ). Chlorogenic (peak 3, RT: $22.67 \mathrm{~min}$ ) and caffeic (peak 4, RT: $25.24 \mathrm{~min}$ ) acids were found as the most abundant phenolic acids. In addition, two flavonoids, rutin (peak 6, RT: $36.03 \mathrm{~min}$ ) and kaempferol (peak 7, $39.87 \mathrm{~min}$ ), were also found.

HPLC analysis of an ethanolic extract of this plant showed five major phenolics with caffeic and chlorogenic acids as primary phenolic acids. Both compounds have been reported as major phenolic compounds in various plants like Hypericum perforatum, Salvia officinalis, Linum usitatissimum, Punica granatum (Apak et al., 2007). The scavenging activity of caffeic acid and standards had been compared in a study conducted by Gülçin (2006). It was found that the DPPH scavenging effect of caffeic acid (93.9\%) was by far higher than Trolox (14.3\%) at the concentration of $20 \mathrm{mg} / \mathrm{mL}$. According to many scientists, the antioxidant capacity of phenolic acids depends on the degree of hydroxylation and the position of hydroxyl groups (Rice-Evans et al., 1996).

The pigment composition in Table 3 showed that the hexane/acetone extract of $L$. camara leaves was made up of five unidentified chlorophylls, which accounted for more than $80 \%$ of the total pigment present in the extracts. In addition, three known carotenoids, zeaxanthin (1.35\%), B-carotene (2.17\%), and lutein (1.15\%), were also identified. Furthermore, two other unidentified carotenoids were found at the percentage of $3.18 \%$ and $8.35 \%$.

Table 3. The major pigments detected in the hexane/acetone extracts of Lantana camara leaves.

\begin{tabular}{ccccc}
\hline Peak & Retention time (min) & $\lambda_{\max }(\mathbf{n m})$ & Compounds & Abundance (\%) \\
\hline 1 & 6.57 & $580,622,690$ & NI Chlorophyll & 21.34 \\
2 & 8.76 & $546,612,634$ & NI Chlorophyll & 5.15 \\
3 & 9.54 & $378,435,495$ & NI Carotenoid & 3.18 \\
4 & 9.96 & $270,418,482$ & NI Carotenoid & 8.35 \\
5 & 12.54 & $444,448,476$ & Zeaxanthin & 1.53 \\
6 & 13.79 & $594,618,646$ & NI Chlorophyll & 11.2 \\
7 & 14.80 & $424,449,468$ & B-Carotene & 2.17 \\
8 & 17.79 & $398,435,465$ & Lutein & 1.15 \\
9 & 24.12 & $528,603,668$ & NI Chlorophyll & 25.77 \\
10 & 28.07 & $534,618,644$ & NI Chlorophyll & 20.16 \\
\hline
\end{tabular}

Fruits, vegetables, and edible plants with a high content of coloring principles are involved in producing "coloring foods". However, orange carrots, sweet potatoes, tomatoes, and spirulina are just a few of many edibles and deeply colored raw materials used (Stich, 2016). V. amygdalina, one of the selected plants for this investigation, is an edible green plant very appreciated by Cameroonians because of its use for cooking of delicious local dish called "ndolé". C. citratus, another 
plant used, is an edible and medicinal green plant. The leaf extracts of this plant are widely used as relaxing herbal tea. A. conyzoides and L. camara are medicinal green plants, and they are usually used to treat malaria and toothache. All these plants displayed extracts with high chlorophyll contents (A. conyzoides and $L$. camara) are associated with carotenoids which could serve as a food-grade dye. Indeed, Martins et al. (2016) reported that chlorophyll (E 140) from Spinacea oleracea leaves and Spirulina pratensis (algae) are already used as a natural coloring agent for beverages, fruit juices, and dairy products.

\section{Antimicrobial activity of the plant extracts}

The results from Table 4 show that the inhibition diameters of the active plant extracts were significantly different $(\mathrm{p}<0.05)$ and varied from $10 \mathrm{~mm}$ to $26 \mathrm{~mm}$ for the vegetative cells and $13.5 \mathrm{~mm}$ to $22 \mathrm{~mm}$ for bacterial spores. Extracts of Aframomum melegueta seeds ( $\mathrm{IZ}=26 \pm 1.4 \mathrm{~mm} ; \mathrm{IZ}=10.8 \pm 0.4 \mathrm{~mm}$ ), Lantana camara leaves $(\mathrm{IZ}=24.8 \pm 0.8 \mathrm{~mm} ; \mathrm{IZ}=27.5 \pm 1.6 \mathrm{~mm})$, and Nauclea diderrichii stem bark $(\mathrm{IZ}=10.5 \pm 0.71 \mathrm{~mm} ; \mathrm{IZ}=11.1 \pm 1.4 \mathrm{~mm})$ were active against Salmonella agona. Hexane/acetone extract of $L$. camara leaves was also more effective than gentamycin $(\mathrm{IZ}=26 \mathrm{~mm})$ against $S$. agona. Except for the extracts from $L$. camara rods, at least one extract from the remaining plant extracts was efficient against Staphylococcus aureus. The efficiency of hexane/acetone extracts of Garcinia kola fruits $(\mathrm{IZ}=15.7 \pm 1.5 \mathrm{~mm}), L$. camara leaves $(\mathrm{IZ}=11.6 \pm 0.6 \mathrm{~mm})$, Vernonia amygdalina leaves $(\mathrm{IZ}=17.3 \pm 1.5 \mathrm{~mm})$, and ethanol/water extract of $N$. diderrichii leaves $(\mathrm{IZ}=15.2 \pm 0.84 \mathrm{~mm}$ ) were shown on L. monocytogenes. Hexane/acetone extracts from Ageratum conyzoides (IZ $=15.5 \pm 2.1 \mathrm{~mm}$ ) and $L$. camara leaves (IZ $=24.8 \pm 3.9 \mathrm{~mm}$ ) were the most active extracts against vegetative cells of $B$. cereus and B. subtilis, respectively. Hexane/acetone extracts of $G$. kola seeds (IZ $=18 \pm 1.4$ $\mathrm{mm}$ and $\mathrm{IZ}=22 \pm 1.4 \mathrm{~mm}$ ) and $L$. camara leaves $(\mathrm{IZ}=18 \pm 1.4 \mathrm{~mm}$ and $\mathrm{IZ}=$ $20.5 \pm 0.7 \mathrm{~mm}$ ) had the most significant effect on germination and outgrowth of Bacillus cereus and Bacillus subtilis spores.

Hexane/acetone extracts of $A$. conyzoides $(\mathrm{IZ}=12 \pm 1.4 \mathrm{~mm})$ and $V$. amygdalina leaves $(\mathrm{IZ}=12 \pm 0 \mathrm{~mm})$ and $L$. camara rods $(\mathrm{IZ}=11.3 \pm 0.4)$ were active against Kluyveromyces spp. In contrast, hexane/acetone extracts of $A$. conyzoides (IZ = $13 \pm 1.4 \mathrm{~mm})$, Cymbopogon citratus leaves $(\mathrm{IZ}=14 \pm 1.4 \mathrm{~mm}), G$. kola fruits (IZ = $17 \pm 1.4 \mathrm{~mm}$ ), and $L$. camara leaves ( $\mathrm{IZ}=14 \pm 1.4 \mathrm{~mm}$ ) were more efficient against Aspergillus. Furthermore, hexane/acetone extract of G. kola displayed higher antifungal activity on Aspergillus than Nystatin $(I Z=14 \mathrm{~mm}$ ) used as a reference compound. None of the analyzed extracts exerted antimicrobial activity against Lactobacillus plantarum and Saccharomyces spp. Furthermore, no inhibition and no growth were noticed with Penicillium expansum for all the extracts. Except for the mentioned cases above, it has been noted that both antibiotics were more effective than extracts. 


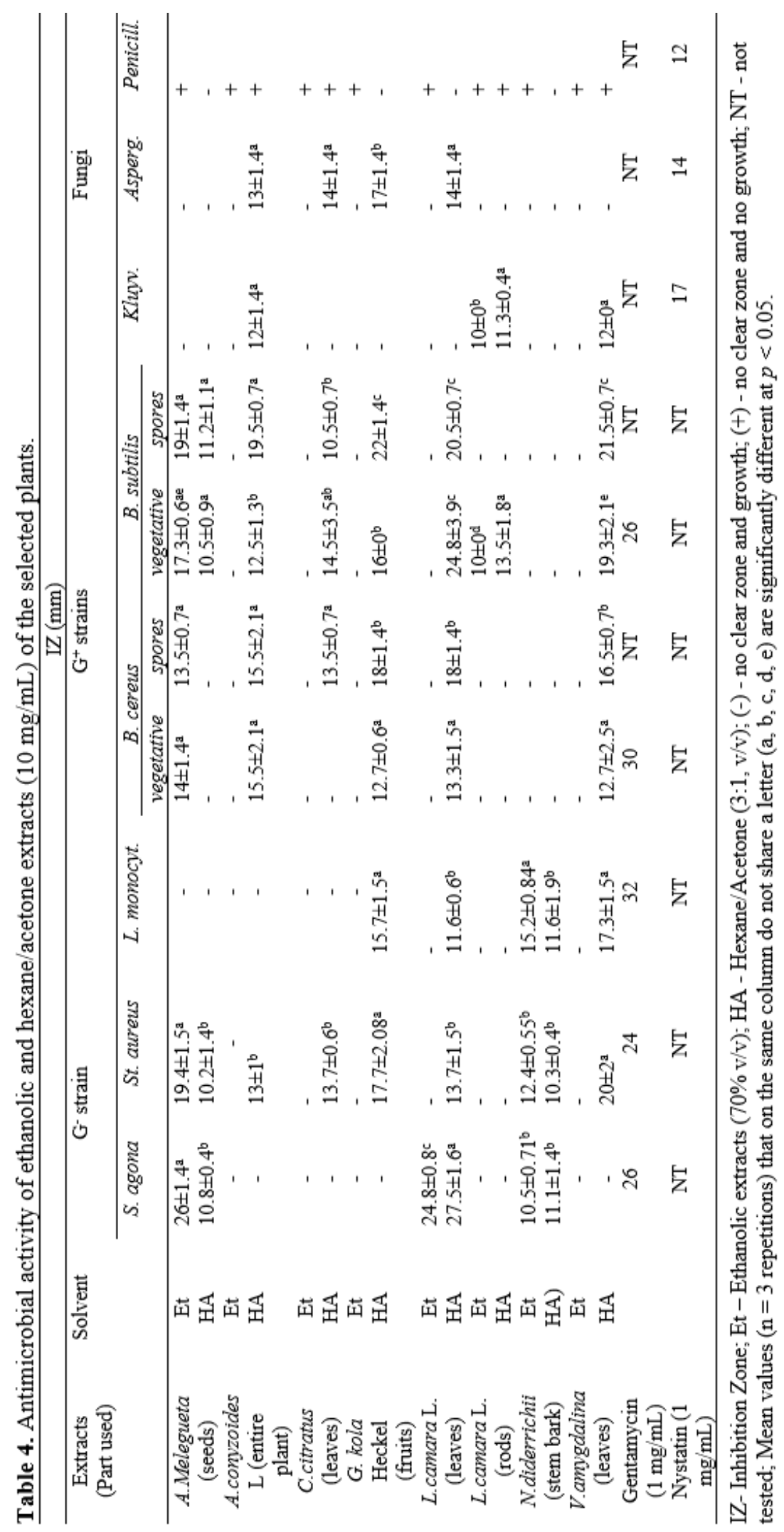




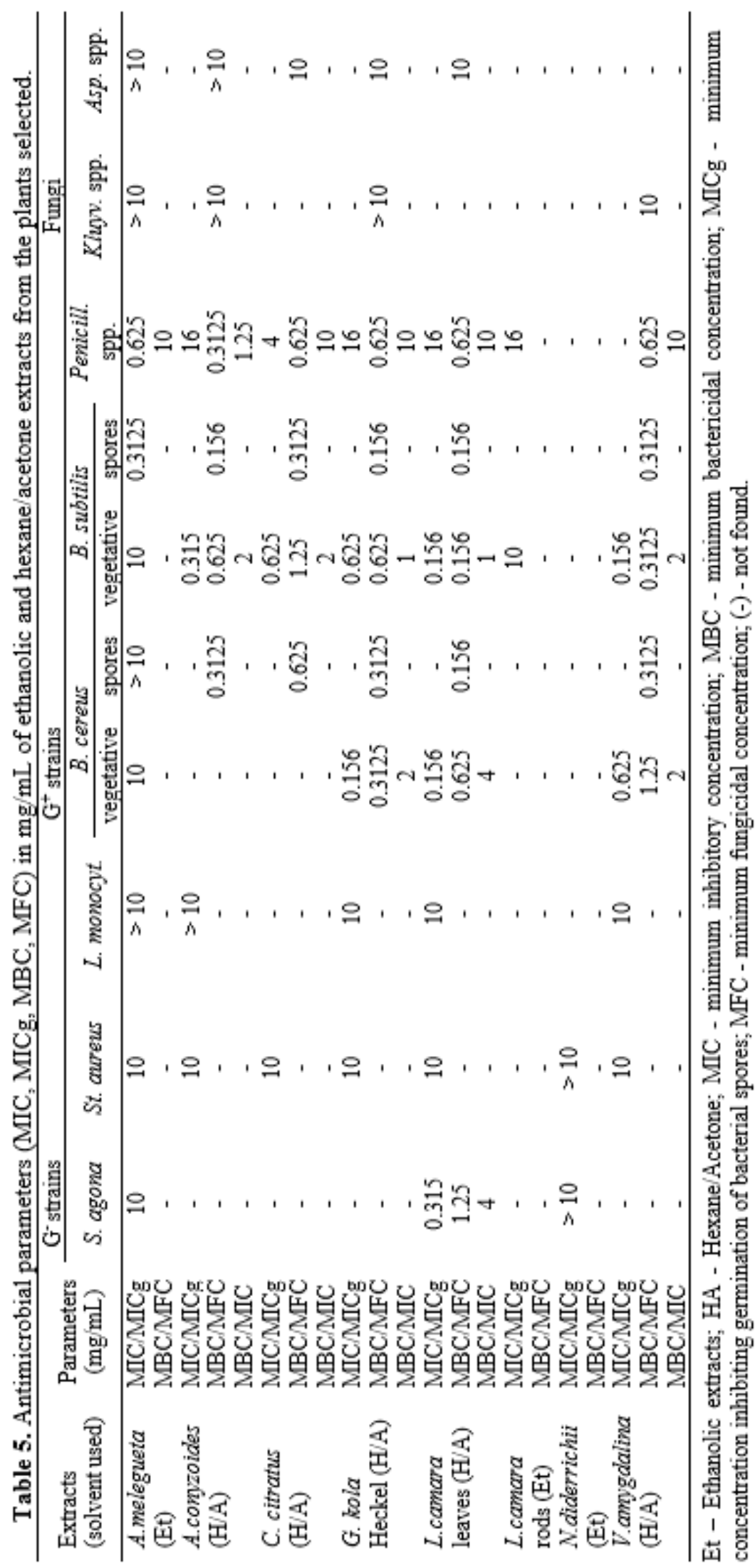


The minimum inhibitory concentration, minimum bactericide concentration, minimum concentration inhibiting bacterial spore germination, minimum fungicidal concentration, and $\mathrm{MB}(\mathrm{F}) \mathrm{C} / \mathrm{MIC}$ of the plant extracts are shown in Table 5. It has been noted that most of the extracts displaying good antimicrobial parameters were obtained from hexane/acetone $(3: 1, \mathrm{v} / \mathrm{v})$ extracts. Vegetative cells and spores of B. cereus and B. subtilis and spores of Penicillium expansum were found more sensitive to extracts.

Hexane/acetone extract from $G$. kola seeds was the most effective extract on the vegetative cells of $B$. cereus by exhibiting a MIC value of $0.156 \mathrm{mg} / \mathrm{mL}$ and MBC value of $0.3125 \mathrm{mg} / \mathrm{mL}$ a bactericidal activity $(\mathrm{MBC} / \mathrm{MIC}=2)$. Hexane/acetone extract of $L$. camara leaves exerted bactericidal effect $(\mathrm{MBC} / \mathrm{MIC}=1)$ on the vegetative cells of $B$. subtilis with MIC and MBC values of $0.156 \mathrm{mg} / \mathrm{mL}$. Except for $N$. diderrichii, the others six plants $(85.7 \%)$ exerted an inhibiting activity on spore germination. The lowest $\mathrm{MICg}$ values were observed with hexane/acetone extract of $L$. camara leaves $(0.156 \mathrm{mg} / \mathrm{mL})$ on B. cereus and B. subtilis spores. Among the most effective plant extracts which exerted an inhibiting effect on Penicillium spp., the extract of $A$. conyzoides was the one that displayed a strong fungistatic activity (MFC/MIC=4). This extract revealed MIC value of 0.312 $\mathrm{mg} / \mathrm{mL}$ and MFC value of $1.25 \mathrm{mg} / \mathrm{mL}$.

Many plant extracts possess antimicrobial activities and are proposed as food preservatives (Lyumugabe et al., 2017; Hintz et al., 2015; Negi, 2012) and food coloring agents (Boo et al., 2012). In this investigation, except for extracts from $A$. melegueta seeds, $L$. camara leaves, and $N$. diderrichii, which were active against Salmonella agona, the remaining extracts were ineffective. This result disagrees with the findings of other authors on the antimicrobial activity of these plants. They reported the antibacterial activity of methanol extracts from A. conyzoides leaves, methanol, and water extracts from C. citratus leaves (Prakash et al., 2016), and ethanol extracts from $V$. amygdalina and L. camara leaves (Lyumugabe et al., 2017) against Salmonella spp. However, hexane/acetone extracts showed good antimicrobial activity against bacteria ( $S$. aureus, L. monocytogenes, $B$. cereus, and $B$. subtilis), spore-forming bacteria (B. cereus and B. subtilis), and some fungi (Penicillium spp. and Aspergillus spp.). In the same line, Kumar et al. (2017) reported that acetone extracts of $L$. camara leave and flowers exhibited intense antimicrobial activity against Bacillus subtilis, Lactobacillus spp., S. aureus, Penicillium spp., Aspergillus niger which are among the most dangerous food spoilage and food poisoning microorganisms. Though the antimicrobial activity of hexane/acetone extracts seems different depending on the strains of bacteria and the fungi, it was demonstrated from the multivariate analysis that the antimicrobial efficiency of these extracts is positively correlated to their contents in chlorophyll and carotenoids. In consistence with our results, it is apparent that some plant extracts are bactericidal. This study showed that extracts from G. kola fruits, $L$. camara, and $V$. amygdalina leaves exerted bactericidal effects against B. cereus and $B$. subtilis, food poisoning, and food spoilage bacteria. In contrast, extract from A. conyzoides displayed a fungicidal effect on Penicillium spp. Our results also 
revealed the inhibitory effect of some extracts on germination of B. cereus and $B$. subtilis spores. In agreement with the present study, Voundi et al. (2015) studied the anti- germinating activity of some Cameroonian plants' essential oils (EOs) on pathogenic and spoilage spores of Bacillus spp. They reported that EOs from A. conyzoides and $C$. citratus exerted an inhibitory effect on the germination of spores of B. cereus and B. subtilis. Hexane/acetone extracts were found more active on gram-positive than gram-negative bacteria. This suggests that fatty-soluble pigments present in hexane/acetone extracts might exert their antimicrobial activity by disorganization of the cell wall and leakage of cytoplasm material (Gyawali et al., 2015). Even if the reason for antimicrobial activity of carotenoids is still poorly understood, previous reports suggested that $B$-carotene could lead to the accumulation of lysozyme, and antibacterial immune enzyme that digests bacterial cell walls, therefore generating the antibacterial activity (Bhagavathy et al., 2011). This study revealed that all extracts analyzed did not have an antifungal effect against Saccharomyces spp. Lyumugabe et al. (2017) reported a similar effect with other plant extracts. Therefore, this finding is reassuring for their potential use as preservatives in indigenous sorghum beers because of the role as a starter played by $S$. cerevisiae in the fermentation stage.

\section{Multivariate analysis}

To analyze the correlations between the measured variables during the testing of extracts, the principal component analysis (PCA) was applied to seven parameters belonging to phytochemical, antioxidant, and antimicrobial variables, as shown in Figures $3 \mathrm{a}$ and $3 \mathrm{~b}$. The variables were reduced into two principal components (PC1 and PC2) with eigenvalues more significant than 1. PC1 and PC2 accounted for $39.85 \%$ and $39.41 \%$, respectively, and explained together $79.26 \%$ of the total variance after varimax rotation. The PCA analysis showed that antimicrobial activity, carotenoids, $\mathrm{Chl}$ a, and $\mathrm{Chl} \mathrm{b}$ contributed positively to $\mathrm{PC}$.

A strong positive correlation between carotenoids, $\mathrm{Chl}$ a, $\mathrm{Chl} b$ contents of the extracts, and the antimicrobial activity of the plant extracts. Phenols and flavonoids were positively correlated to the scavenging activity of the extracts, being strongly loaded on the positive side of the component PC2. The scores plot displayed that ethanol/water extract of A. melegueta seeds had the highest phenols and flavonoids contents and the best DPPH scavenging activity (figure 3b). Furthermore, the scores plot confirmed that most hexane/acetone extracts present the best antimicrobial activity.

A cluster analysis was applied using the centroid method and squared Euclidean measurement to interpret the relationship between the different tested extracts based on their phytochemical contents and biological activity. The centeredreduced normalization was applied to improve the classification of the extracts. Figure $3 \mathrm{c}$ shows a dendrogram of the sixteen extracts. In figure 3, two main clusters marked down, and three major sub-clusters, I, II, and III, were revealed. The first sub-cluster was formed by all ethanolic extracts and hexane/acetone extracts of A. melegueta seeds, $G$. kola fruits, $L$. camara rods, $N$. diderrichii stem bark. Hexane/acetone extracts of A. conyzoides, C. citratus leaves, L. camara 
leaves, and $V$. amygdalina leaves were classified into the second sub-cluster with a close relationship between A. conyzoides and L. camara extracts. Ethanol/water extract of A. melegueta seeds formed the third sub-cluster.

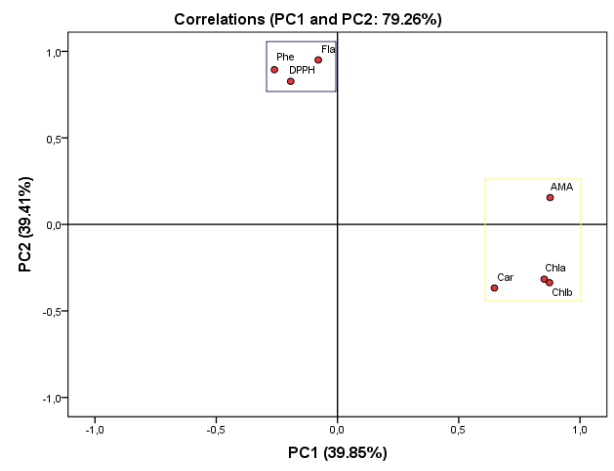

a)

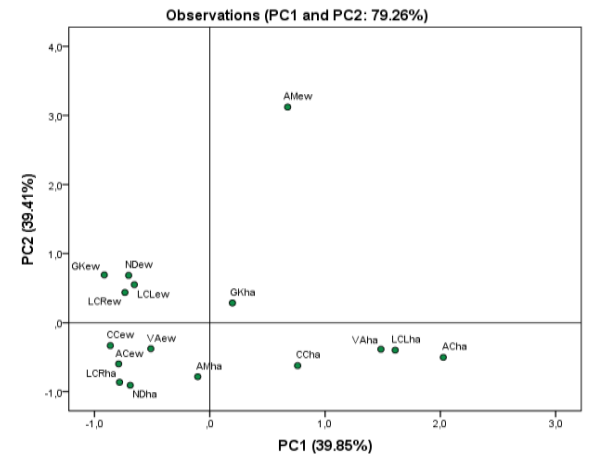

b)

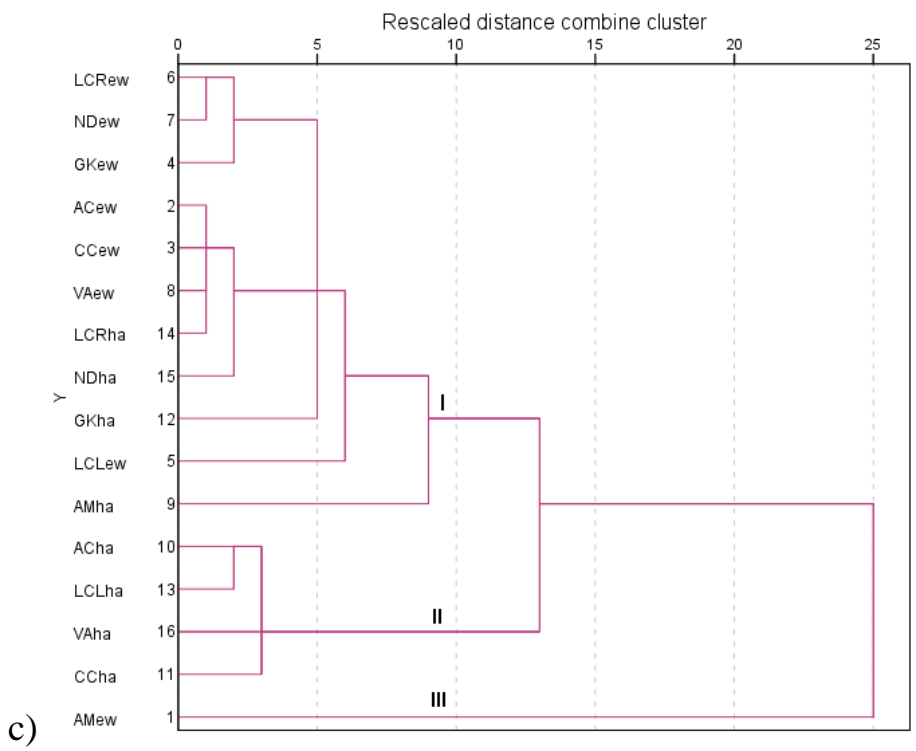

Figure 3. Principal component analysis of correlation loadings (a) and scores (b) plots derived using phytochemical, the biological activity of extracts. Dendrogram (c) of extracts from different solvent systems was performed with the hierarchical cluster analysis using the centroid method and squared Euclidean measurement. Rotation method: varimax with Kaizer normalization $(\mathrm{KMO}=0.753 ; p<0.001)$. $\mathrm{x}$-axis and $\mathrm{y}$-axis mean rescaled distance cluster and the plant extracts measured. AMA - antimicrobial activity as a sum of the inhibition diameter obtained from each plant extract; Car - carotenoids; Chl a - chlorophylla; Chl b - chlorophyll b; DPPH - DPPH scavenging activity; Fla - flavonoids; Phe phenols; AM - Aframomum melegueta; AC - Ageratum conyzoides; CC - Cymbopogon citratus; GK - Garcinia kola; LCL and LCR - Lantana camara leaves and rods; ND Nauclea diderrichii; VA - Vernonia amygdalina; ew - ethanol/water; ha - hexane/acetone. 
Excessive formation of free radicals accelerates the oxidation in foods and biological systems. Therefore, radical scavenging activity of natural compounds is significant for food quality and consumer health. Free radical scavenging is one of the known mechanisms by which antioxidants inhibit lipid oxidation. This test is a standard assay in antioxidant activity studies and offers a rapid technique for screening the radical-scavenging ability of specific compounds or extracts. In this study, all the extracts had expressed a scavenging activity. The antioxidant potential of extracts showed the highest scavenging activity with ethanol/water extracts and the lowest for hexane/acetone extracts. Principal component analysis (PCA) revealed that the DPPH radical scavenging activity appears to depend on phenols and flavonoid contents of the extracts (figure 3). This finding agrees with what Boo et al. (2012) reported, where the antioxidant properties of thirteen kinds of natural plant pigments were evaluated using different extraction procedures. They demonstrated that the scavenging activity was correlated with the total phenols and flavonoids contents present in aqueous and ethanolic extracts.

\section{Conclusions}

In this study, seven edible and Cameroonian medicinal plants exhibited an appreciable antioxidant activity. Apart from Saccharomyces spp. MIUG D8 and Lactobacillus plantarum, all other tested microorganisms were sensitive to at least one plant extract. B. cereus and Listeria monocytogenes were affected by $31.25 \%$ of the extracts tested, while Salmonella agona was affected by $37.5 \%$ of the extracts. Nine extracts were active against $B$. subtilis and $S$. aureus $(56.25 \%)$. The extracts inhibited the germination of food poisoning and food spoilage spores by $37.5 \%$. Aspergillus niger and Kluyveromyces spp. MIUG M26 were sensitive to 4 $(25 \%)$ different extracts. This antimicrobial activity has been related to the natural fatty-soluble pigments contained in the extracts. According to the results, some of the plant extracts might valuably increase the shelf life of foodstuffs, replace synthetic antioxidants, and prevent cellular damage, cause of aging, and human diseases. In addition, antibacterial activity and food colorant properties might be exploited to find natural preservative ingredients in the food industry. Therefore, a strong interest should be given to some selected plants because of their great potential as a natural antioxidant (L. camara), food preservatives ( $L$. camara, C. citratus, V. amygdalina), and food colorant (L. camara, A. conyzoides). However, further evaluation of the biological activity of these extracts against a larger microbial panel and toxicity studies are needed to reinforce the potential of the candidate plant extracts for these purposes.

\section{Acknowledgments}

This study was supported by Eugen Ionescu Grant co-funded by Romanian Government and the Agence Universitaire de la Francophonie (AUF). The authors would like to extend their gratitude to the Integrated Center for Research, Expertise, and Technological Transfer in Food Industry (BIOALIMENT) of 
"Dunarea de Jos" University of Galati for the technical support provided in this study.

\section{References}

Agnaniet, H., Mbot, E. J., Keita, O., Fehrentz, J.-A., Ankli, A., Gallud, A., et al. 2016. Antidiabetic potential of two medicinal plants used in Gabonese folk medicine. BMC Complementary and Alternative Medicine, 16, 13-20.

Amchova, P., Kotolova, H., and Ruda-Kucerova, J. 2015. Health safety issues of synthetic food colorants. Regulatory Toxicology and Pharmacology, 73, $914-922$.

Andrews, J. M. 2001. Determination of minimum inhibitory concentration. Journal of Antimicrobial Chemotherapy, 48, 5-16.

Apak, R., Güçlü, K., Demirata, B., Özyürek, M., Çelik, S. E., Bektaşoğlu, B. et al. (2007). Comparative evaluation of various total antioxidant capacity assays applied to phenolic compounds with the CUPRAC assay. Molecules, 12, 1496-1547.

Ascension, N. M., Del Florence, M. N. E., Florentine, N. F., François-Xavier, E., Menut, C. 2017. Bioactivity of essential oils from medicinal plants of Cameroon and their combination against infant diarrhea induced by bacteria. African Journal of Traditional, Complementary and Alternative Medicines, 14, 27-37.

Bhagavathy, S., Sumathi, P., and Bell, I.J.S. 2011. Green algae Chlorococcum humicola-a new source of bioactive compounds with antimicrobial activity. Asian Pacific Journal of Tropical Biomedicine, 1, 1-7.

Bayoï, J. R., Djoulde, D. R., Kamga, P. B., Nyegue, M., Olugu, S. V., Bakary, D., and Etoa, F. X. 2014. Activity of acetic acid on Bacillus stearothermophilus and Bacillus subtilis spores after sublethal heat pretreatments. International Journal of Innovation and Scientific Research, 10, 570-575.

Bolea, C. A., and Vizireanu, C. 2017. Polyphenolic content and antioxidant properties of black rice flour. The Annals of the University Dunarea de Jos of Galati. Fascicle VIFood Technology, 41, 75-85.

Boo, H.-O., Hwang, S.-J., Bae, C.-S., Park, S.-H., Heo, B.-G., and Gorinstein, S. 2012. Extraction and characterization of some natural plant pigments. Industrial Crops and Products, 40, 129-135.

Breda, C. A., Gasperini, A. M., Garcia, V. L., Monteiro, K. M., Bataglion, G. A., Eberlin, M. N., and Duarte, M. C. T. 2016. Phytochemical Analysis and Antifungal Activity of Extracts from Leaves and Fruit Residues of Brazilian Savanna Plants Aiming Its Use as Safe Fungicides. Natural Products and Bioprospecting, 6, 195-204.

Cock, I. E., and van Vuuren, S. 2015. South African food and medicinal plant extracts as potential antimicrobial food agents. Journal of Food Science and Technology, 52, 6879 -6899 .

Contreras, R.N., Ruter, J.M., Owen, J.S., and Hoegh, A. 2013. Chlorophyll, carotenoid, and visual color rating of Japanese-cedar grown in the Southeastern United States. HortScience, 48(12), 1452-1456.

Dadi, D. W., Emire, S. A., Hagos, A. D., and Eun, J. B. 2019. Effect of UltrasoundAssisted Extraction of Moringa stenopetala Leaves on Bioactive Compounds and Their Antioxidant Activity. Food Technology and Biotechnology, 57, 77-86.

Dahmoune, F., Spigno, G., Moussi, K., Remini, H., Cherbal, A., and Madani, K. 2014. Pistacia lentiscus leaves as a source of phenolic compounds: Microwave-assisted extraction optimized and compared with ultrasound-assisted and conventional solvent extraction. Industrial Crops and Products, 61, 31-40. 
Elbatanony, M. M., El-Feky, A. M., Hemdan, B. A., and Azab El-Liethy, M. 2019. Assessment of the antimicrobial activity of the lipoidal and pigment extracts of Punica granatum L. leaves. Acta Ecologica Sinica, 39, 89-94.

Esiegwu, A. C., Okoli, I. C., Emenalom, O. O., Esonu, B. O., and Udedibie A. B. I. 2014. The Emerging nutraceutical benefits of the African wonder nut (Garcinia kola): A Review. Global Journal of Animal Scientific Research, 2, 170 - 183.

Espinel-Ingroff, A., 2007. Standardized disk diffusion method for yeasts. Clinical Microbiology Newsletter, 29(13), 97-100.

Gülçin, İ. 2006. Antioxidant activity of caffeic acid (3, 4-dihydroxycinnamic acid). Toxicology, 217, 213-220.

Gyawali, R., Hayek, S. A., and Ibrahim, S. A. 2015. In Plant extracts as antimicrobials in food products, ed. by T.M. Taylor. Handbook of Natural Antimicrobials for Food Safety and Quality, 49-68 (Elsevier, Woodhead Publishing).

Hintz, T., Matthews, K. K., and Di, R. 2015. The Use of Plant Antimicrobial Compounds for Food Preservation. BioMed Research International, 115, 1-12.

Idhan, A., Nadir, M., and Kadir, M. 2018. Paddy chlorophyll concentrations in drought stress condition and endophytic fungi application. IOP Conference Series: Earth and Environmental Science, 156(1), p. 12-40.

Kirby-Lee, K.A. 2019. Antimicrobial activity of extracts from exotic fruits and vegetables. http://dx.doi.org/10.7287/peerj.preprints.3373, Accessed 30 November 2019.

Kumar, A., Singh, S., and Saini, P. 2017. Assessment of Phytochemical Constituents and Antimicrobial Activity of Lantana Camara L. Biosciences, Biotechnology Research Asia, 14, 977-984.

Ladoh-Yemeda, C., Vandi, T., Dibong, S., Mpondo Mpondo, E., Wansi, J., Betti, J. et al. 2016. Étude ethnobotanique des plantes médicinales commercialisées dans les marchés de la ville de Douala, Cameroun. Journal of Applied Biosciences, 99, 9450 - 9466.

Lucera, A., Costa, C., Conte, A., and Del Nobile, M. A. 2012. Food applications of natural antimicrobial compounds. Frontiers in Microbiology, 3, 27-37.

Lyumugabe, F., Primitive, J., Bayingana, C., \& Bajyana So, E. (2017). Antimicrobial Activity and Phytochemicals Analysis of Vernonia aemulans, Vernonia amygdalina, Lantana camara and Markhamia lutea Leaves as Natural Beer Preservatives. Am. J. Food Technol. 12, 35-42.

Martins, N., Roriz, C. L., Morales, P., Barros, L., and Ferreira, I. C. F. R. 2016. Food colorants: Challenges, opportunities and current desires of agro-industries to ensure consumer expectations and regulatory practices. Trends food Sci. Tech. 52, 1-15.

Meot-Duros, L., Le Floch, G., Magné, C. 2008. Radical scavenging, antioxidant and antimicrobial activities of halophytic species. Journal of Ethnopharmacology, 116, 258-262.

Negi, P. S. 2012. Plant extracts for the control of bacterial growth: efficacy, stability and safety issues for food application. International Journal of Food Microbiology, 156, 717.

Olajuyigbe, O. O., Adedayo, O., and Coopoosamy, R. M. 2020. Antibacterial activity of defatted and non-defatted methanolic extracts of Aframomum melegueta k. schum. against multi-drugresistant bacteria of clinical importance. The Scientific World Journal, Article ID 4808432, 2020, 8 pages.

Onoja, S. O., Omeh, Y. N., Ezeja, M. I., and Chukwu, M. N. 2014. Evaluation of the in vitro and in vivo antioxidant potentials of Aframomum melegueta methanolic seed extract. Journal of tropical medicine, 12, 25-31. 
Pękal, A., and Pyrzynska, K. 2014. Evaluation of Aluminium Complexation Reaction for Flavonoid Content Assay. Food Analytical Methods, 7, 1776 -1782.

Prakash, S., Ramasubburayan, R., Ramkumar, V. S., Kannapiran, E., Palavesam, A., and Immanuel, G. 2016. In vitro-Scientific evaluation on antimicrobial, antioxidant, cytotoxic properties and phytochemical constituents of traditional coastal medicinal plants. Biomedicine and Pharmacotherapy, 83, 648-657.

Rice-Evans, C. A., Miller, N. J., and Paganga, G. 1996. Structure-antioxidant activity relationships of flavonoids and phenolic acids. Free radical biology and medicine, $\mathbf{2 0}$ 933-956.

Rodriguez-Amaya, D. B. 2016. Natural food pigments and colorants. Current Opinion in Food Science, 7, 20-26.

Silveira, C.P., Torres-Rodríguez, J.M., Alvarado-Ramírez, E., Murciano-Gonzalo, F., Dolande, M., Panizo, M. and Reviakina, V., 2009. MICs and minimum fungicidal concentrations of amphotericin B, itraconazole, posaconazole and terbinafine in Sporothrix schenckii. Journal of medical microbiology, 58(12), 1607-1610.

Shahinuzzaman, M., Yaakob, Z., Anuar, F. H., Akhtar, P., Kadir, N. H. A., Hasan, A. K. M et al. 2020. In vitro antioxidant activity of Ficus carica L. latex from 18 different cultivars. Scientific Reports, 10, 1-14.

Stich, E. In Food Color and Coloring Food, ed. by R. Carle, R. Schweiggert. 2016. Handbook on Natural Pigments in Food and Beverages, 1t ${ }^{\text {st }}$ edn. 3-27 (Elsevier, Woodhead Publishing).

Voundi, S. O., Nyegue, M., Lazar, I., Raducanu, D., Ndoye, F. F., Stamate, M., Etoa, F.-X 2015. Effect of Essential Oils on Germination and Growth of Some Pathogenic and Spoilage Spore-Forming Bacteria. Foodborne Pathogens and Disease, 12, 551-559.

Zhang, L.-L., Zhang, L.-F., and Xu, J.-G. 2020. Chemical composition, antibacterial activity and action mechanism of different extracts from hawthorn (Crataegus pinnatifida Bge.). Scientific Reports, 10, 1-13.

Złotek, U., Mikulska, S., Nagajek, M., and Świeca, M. 2016. The effect of different solvents and number of extraction steps on the polyphenol content and antioxidant capacity of basil leaves (Ocimum basilicum L.) extracts. Saudi Journal of Biological Sciences, 23, 628-633. 